\title{
The application of inelastic neutron scattering to explore the significance of a magnetic transition in an iron based Fischer-Tropsch catalyst that is active for the hydrogenation of $\mathrm{CO}$
}

\author{
Robbie Warringham, Andrew R. McFarlane, Donald A. \\ MacLaren, Paul B. Webb, Robert P. Tooze, Jon Taylor, \\ Russell A. Ewings, Stewart F. Parker and David Lennon
}

\section{Published version information}

Citation: Warringham, R et al. "The application of inelastic neutron scattering to explore the significance of a magnetic transition in an iron based Fischer-Tropsch catalyst that is active for the hydrogenation of CO". Journal of Chemical Physics, vol. 143, no. 17 (2015): 174703.

doi: http://dx.doi.org/10.1063/1.4935054

This version is made available in accordance with publisher policies. Please cite only the published version using the reference above. 


\section{The application of inelastic neutron scattering to explore the}

significance of a magnetic transition in an iron based Fischer-Tropsch catalyst that is active for the hydrogenation of CO

Robbie Warringham ${ }^{1}$, Andrew R. McFarlane ${ }^{1}$, Donald A. MacLaren ${ }^{2}$, Paul B. Webb ${ }^{3}$, Robert P. Tooze ${ }^{3}$, Jon Taylor ${ }^{4}$, Russell A. Ewings ${ }^{4}$, Stewart F. Parker ${ }^{4}$ and David Lennon ${ }^{1 *}$

1. School of Chemistry, Joseph Black Building, University of Glasgow, Glasgow, G12 8QQ, Scotland, UK.

2. School of Physics and Astronomy, the Kelvin Building, University of Glasgow, Glasgow, G12 8QQ, Scotland, UK.

3. Sasol Technology UK Ltd, Purdie Building, North Haugh, St Andrews, Fife, KY16 9ST, UK.

4. ISIS Facility, STFC Rutherford Appleton Laboratory, Chilton, Didcot, Oxon OX11 0QX, UK.

Email: David.Lennon@glasgow.ac.uk 


\begin{abstract}
An iron based Fischer-Tropsch synthesis catalyst is evaluated using CO hydrogenation at ambient pressure as a test reaction and is characterised by a combination of inelastic neutron scattering (INS), powder X-ray diffraction, temperature-programmed oxidation, Raman scattering and transmission electron microscopy. The INS spectrum of the as-prepared bulk iron oxide pre-catalyst (hematite, $\alpha-\mathrm{Fe}_{2} \mathrm{O}_{3}$ ) is distinguished by a relatively intense band at $810 \mathrm{~cm}^{-1}$, which has previously been tentatively assigned as a magnon (spinon) feature. An analysis of the neutron scattering intensity of this band as a function of momentum transfer unambiguously confirms this assignment. Post-reaction, the spinon feature disappears and the INS spectrum is characterised by the presence of a hydrocarbonaceous overlayer. A role for the application of INS in magnetic characterisation of iron based FTS catalysts is briefly considered.
\end{abstract}

\title{
$\underline{\text { Keywords }}$
}

Inelastic neutron scattering; Fischer-Tröpsch synthesis; iron Fischer-Tröpsch synthesis catalyst; magnetic transitions; spinon. 


\section{Introduction}

Fischer-Tropsch synthesis (FTS) is a well-established catalytic reaction system that uses synthesis gas $\left(\mathrm{CO}\right.$ and $\mathrm{H}_{2}$ ) obtained from resources such as coal, natural gas and biomass to produce a variety of valuable hydrocarbon products ${ }^{1,2}$. Despite wide application, there remains considerable uncertainty as to how FTS catalysts precisely operate: active FTS catalysts are thought to experience a "construction phase" under reaction conditions in processes of self-organisation ${ }^{3,4}$.

Increasingly, inelastic neutron scattering (INS) is finding application in heterogeneous catalysis $^{5-9}$ and it is applied here to investigate a high specification iron-based FTS catalyst. Previous work by Hamilton and co-workers used INS to study a bulk iron oxide catalyst, using the hydrogenation of $\mathrm{CO}$ at ambient pressure as a test reaction. That work demonstrated the formation of a hydrocarbonaceous overlayer upon reaction and proposed a reaction scheme that accounted for the evolution of the hematite pre-catalyst into an active catalyst capable of supporting CO hydrogenation 10. Whereas it is acknowledged that the hydrogenation of $\mathrm{CO}$ to $\mathrm{CH}_{4}$ cannot be regarded as FTS chemistry, as no polymerisation reaction takes place, it does address aspects of $\mathrm{Fe} / \mathrm{CO} / \mathrm{H}_{2}$ surface chemistry that have connectivity to the molecular transformations associated with FTS ${ }^{10}$. The resulting knowledge base can then be applied to the more complex FTS scenario in due course. Interestingly, the work of Hamilton et al. showed that CO hydrogenation over their unsupported Fe catalyst yielded a similar INS spectrum to that reported for an industrial grade catalyst taken from a commercial FTS reactor ${ }^{11}$. Subsequent INS studies by Warringham et al. examined the same bulk iron oxide catalyst as investigated by Hamilton et al. ${ }^{10}$ and demonstrated how the form of the hydrocarbonaceous overlayer and the reaction 
profile could be modified by a pre-reduction stage prior to syngas exposure ${ }^{12}$. That work connected with an earlier study by Govender, de Croon and Schouten that featured predominantly desorption based experimental techniques ${ }^{13}$.

The present study builds on the successes of the previous INS studies of iron based FTS catalysts ${ }^{10-12}$ and progresses three new concepts. Firstly, a new high specification iron based FTS catalyst is examined (high surface area and homogeneous crystallite size), which has been prepared by a more precisely controlled process than used previously. Van der Loosdrecht et al describe the importance of experimental control in preparing iron FTS catalysts. ${ }^{1}$ Specifically, the precipitation stage is strongly $\mathrm{pH}$ and temperature dependent. Imprecise control of these parameters may lead to an inhomogeneous distribution of crystallite size and, moreover, may induce the presence of different phases of iron oxide, e.g. goethite. ${ }^{1}$ Whereas the original in-house bulk iron catalyst followed standard preparative procedures ${ }^{14}$, the preparative treatments were performed manually. ${ }^{10}$ In order to improve sample homogeneity, an automated catalyst preparation procedure is used here to produce a high specification hematite $\left(\alpha-\mathrm{Fe}_{2} \mathrm{O}_{3}\right)$ pre-catalyst.

Secondly, the original reaction test apparatus commissioned at the Central Facility to accommodate the reaction testing of the large sample sizes necessary for INS measurements has been upgraded ${ }^{15}$ to facilitate better control of the reaction conditions for scaled-up samples. Thirdly, a further attribute of the INS technique, namely the ability of neutron scattering to probe magnetic transitions, has been employed to ascertain whether a relatively intense band observed in the INS spectrum of the pre-catalyst at $810 \mathrm{~cm}^{-1}$ is a magnetic transition. Hamilton and co-workers 
tentatively assigned this band to a magnon, which more correctly can be classified as a spinon ${ }^{10,16}$; the formal assignment of this spectral feature is the main objective of the present work.

Chernavskii and co-workers have previously considered the role of magnetic transitions in FTS catalysts ${ }^{16}$. Given that ferromagnetic metals such as nickel, cobalt and iron based catalysts are active for FTS, Chernavskii et al. discuss the magnetic properties of these materials in relation to FTS activity. For iron FTS catalysts, the degree of magnetisation can be correlated with the reduction of supported $\mathrm{Fe}_{2} \mathrm{O}_{3}$ samples; it can also be used to access the kinetics of iron carburization in carbon monoxide hydrogenation ${ }^{16}$. In this way, Chernavskii et al.'s studies show how the magnetisation of iron based FTS catalysts can be used as a further characterisation tool, that supplements the more traditional array of solid state probes such as X-ray absorption spectroscopy, Mössbauer spectroscopy, X-ray photoelectron spectroscopy, X-ray diffraction, etc.

The present paper is comprised as follows. A micro-reactor arrangement is used to define the CO hydrogenation reaction profile over a $6 \mathrm{~h}$ period for a hematite FTS pre-catalyst that has been prepared using automated control of the precipitation stage of the preparative process. Previous INS measurements examined a comparable hematite FTS catalyst that had undergone reaction testing at two temperatures: 623 and $723 \mathrm{~K}^{10}$. However, for the more highly specified catalyst under examination here, a single reaction temperature of $623 \mathrm{~K}$ has been selected. Post-reaction, that sample is characterised by powder X-ray diffraction (XRD), temperature-programmed oxidation (TPO), Raman scattering and transmission electron microscopy (TEM). A 
larger quantity of this catalyst is then exposed to syngas at $623 \mathrm{~K}$, transferred to the MARI spectrometer of the ISIS Facility and the INS spectrum acquired.

The MARI spectrometer is a direct geometry chopper instrument, which uses a Fermi chopper to monochromate the incident neutron beam to give incident energies in the range $72-8060 \mathrm{~cm}^{-1} 17$. The energy resolution is $\approx 2 \%$ of the incident energy at the largest energy transfer and degrades with decreasing energy transfer. Selection of an incident energy close to the vibrational transitions of interest then offers good resolution at the cost of restricted spectral range. The detectors on MARI cover a wide range of scattering angles, which allow simultaneous determination of both energy $\left(\omega, \mathrm{cm}^{-1}\right)$ and momentum $\left(Q, \AA^{-1}\right)$ exchange during the scattering process. Thus, INS on MARI is intrinsically a two-dimensional spectroscopy. This capability will be exploited to analyse the magnetic properties of this iron based Fischer-Tropsch catalyst.

After spectral acquisition, the INS reacted sample is further characterised by XRD, TPO, Raman and TEM. The INS spectra before and after reaction indicate that a specific magnetic transition, i.e. a spinon, is associated with the hematite FTS precatalyst but that this entity has no association with $\mathrm{CO}$ hydrogenation activity. Collectively, these studies provide further understanding on the form of iron based FTS catalysts throughout various stages of the CO hydrogenation reaction coordinate. This heightened awareness of catalyst attributes helps better define the physicochemical properties that favour CO turnover for this economically important reaction system. 


\section{Experimental}

\section{A. Catalyst preparation}

The iron oxide catalyst samples were prepared by precipitation from a mixture of iron nitrate (Sigma Aldrich, $99.99 \%$ ) and sodium carbonate (Sigma Aldrich, $99.99 \%$ ) using a Mettler Toledo LabMax batch reactor apparatus (Equation 1, Fig. S1 of Supplementary Material).

$$
\begin{gathered}
3 \mathrm{Na}_{2} \mathrm{CO}_{3}(\mathrm{aq})+2 \mathrm{Fe}\left(\mathrm{NO}_{3}\right)_{3}(\mathrm{aq}) \\
+3 \mathrm{H}_{2} \mathrm{O}_{(\mathrm{l})} \rightarrow 6 \mathrm{NaNO}_{3}(\mathrm{aq}) \\
\left.2 \mathrm{Fe}(\mathrm{OH})_{3(\mathrm{~s})} \rightarrow \alpha-\mathrm{Fe}_{2} \mathrm{O}_{3(\mathrm{~s})}+3 \mathrm{H}_{2} \mathrm{O}\right)_{(\mathrm{g})}
\end{gathered}
$$

Iron nitrate was dissolved in deionised water and added drop wise to a heated (357 K) solution of sodium carbonate and 1 litre of deionised water under constant agitation. The iron nitrate was added until the $\mathrm{pH}$ of the solution reached 6.5, then maintained for 16 minutes. The resulting slurry was filtered and washed with warm deionised water and calcined (Equation 2) following a step-wise heating program attaining a maximum of $623 \mathrm{~K}$ overnight. The calcined iron oxide catalyst has a reddish brown colouring. The sample was subsequently ground and sieved to a particle size range of 250 to $500 \mu \mathrm{m}$. No chemical modifiers/promoters were used in the studies described here.

\section{B. Micro-reactor measurements}

Initial reaction testing was performed at ambient pressure (ca. $1.10 \mathrm{~atm})$ using a micro-reactor composed of 1/8” diameter stainless steel Swagelok tubing (Fig S2) ${ }^{8,9}$. Approximately $40 \mathrm{mg}$ of catalyst was loaded into a $1 / 4$ " quartz tube reactor with the 
reactor plugged with quartz wool. The reactor is housed within a tube furnace (Carbolite MTF 10/15/30) equipped with PID control. A thermocouple is positioned within the catalyst bed to ensure accurate temperature reading during measurements. For CO hydrogenation reactions, gas flows of carbon monoxide (3.35 sccm, CK Gas, 99.8 \%), hydrogen (6.75 sccm, BOC Ltd, $99.8 \%$ ) and helium (21.25 sccm BOC Ltd, $99.99 \%$ ) were established over the bypass before introduction to the reactor (WHSV $\left.=12.71 \mathrm{~h}^{-1}\right)^{18}$. All gas flows were monitored using an in-line quadrupole mass spectrometer (Hiden Analytical, HPR-20) attached to the reactor exit line via a differentially-pumped, heated quartz capillary. The sample was subjected to a temperature ramp of $5 \mathrm{~K} \mathrm{~min}^{-1}$ to $623 \mathrm{~K}$ and held for 6 hours. After 6 hours, reactant flows were stopped and the sample allowed to cool to room temperature under the helium carrier gas. For the in situ temperature-programmed oxidation studies, oxygen (5\% in helium, $70 \mathrm{sccm}$, BOC Ltd, $99.0 \%$ ) was introduced to the sample and the reactor heated to $1173 \mathrm{~K}$ at $5 \mathrm{~K} \mathrm{~min}^{-1}$. The $\mathrm{CO}_{2}$ signal response was measured using mass spectrometry. Quantification of the $\mathrm{CO}_{2}$ peak area was achieved by measuring the $\mathrm{CO}_{2}$ response from the TPO of known quantities of graphite (Sigma Aldrich, $99.99 \%)^{6}$. For ex situ characterisation of reacted samples, a passivation procedure was followed involving the introduction of small amounts of oxygen to the reactor, gradually increased to atmospheric levels (i.e. $20 \% \mathrm{O}_{2}$ in the gas feed) ${ }^{19}$.

\section{Inelastic neutron scattering measurements}

We have previously reported on problems encountered when using INS to probe heterogeneous catalyst samples ${ }^{10}$. One matter in particular is the large sample mass required for INS measurements that lead to lower space velocities being attainable in the INS reactor located at the Central Facility compared to the more conventional 
laboratory based micro-reactor arrangement. The difference in contact times has meant that, for fixed reaction times, different stages of the reaction coordinate are experienced by the INS samples compared to the reference micro-reactor samples ${ }^{10}$. In an attempt to improve reaction testing capability at the Central Facility, an upgraded test apparatus is now being used. The capabilities and specification of this apparatus are comprehensively described elsewhere ${ }^{20}$. For the first time, associated sample handling procedures for these FTS catalysts have enabled smaller catalyst masses to be used, reducing the difference in gas hourly space velocity experienced by the INS and micro-reactor samples. The sample handling procedures connected with the INS measurements are briefly outlined below.

Approximately $10 \mathrm{~g}$ of catalyst was loaded into an Inconel reactor cell ${ }^{15}$ and attached to the recently commissioned sample preparation apparatus ${ }^{20}$. Before CO hydrogenation measurements at ambient pressure (ca. 1.10 atm), the iron oxide catalyst was heated to $373 \mathrm{~K}$ under flowing helium (1000 sccm, CK Gas, >99.0 \%) overnight to desorb any water present. The reactor was allowed to cool to room temperature and isolated before transfer to an argon-filled glove box (MBraun UniLab MB-20-G, $\left[\mathrm{H}_{2} \mathrm{O}\right]<1 \mathrm{ppm},\left[\mathrm{O}_{2}\right]<2 \mathrm{ppm}$ ) for loading into an aluminium INS cell that is sealed via an indium wire gasket ${ }^{21}$. The sample was then transported to the INS spectrometer and the spectrum recorded at $20 \mathrm{~K}$. All INS measurements were performed using the MARI direct geometry spectrometer, which is located at the ISIS Facility of the Rutherford Appleton Laboratory ${ }^{17}$. Spectra were recorded at incident neutron energies of 4840 and $1613 \mathrm{~cm}^{-1}$ using the A-chopper package ${ }^{22}$. This procedure produced the INS spectrum of the spectrum of the $\alpha-\mathrm{Fe}_{2} \mathrm{O}_{3}$ pre-catalyst. 
A second INS cell was charged and connected to the test apparatus. After a dehydration stage as outlined above, carbon monoxide (75 sccm, CK Gas, 99.97 \%), hydrogen (150 sccm, CK Gas, $99.99 \%$ ) and a carrier gas (helium, 600 sccm, CK Gas, $99.99 \%)$ were passed over the catalyst at ambient pressure (ca. $1.10 \mathrm{~atm})$. These flow arrangements correspond to a WHSV of $1.27 \mathrm{~h}^{-1}$. The reactor was heated to 623 $\mathrm{K}$ at $5 \mathrm{~K} \mathrm{~min}^{-1}$ and held at $623 \mathrm{~K}$ for 6 hours, after which time the reactant gases were stopped and the sample allowed to cool to ambient temperature under a continuous flow of helium. The cell was isolated, transferred to the glove box, the sample decanted to the aluminium sample holder and the INS spectra recorded. After spectral acquisition, the reacted sample was retained in the aluminium sample holder and kept in a storage cupboard for several days, where the slow ingress of air into the cell facilitated passivation of the sample.

\section{Catalyst characterisation}

\section{Pre-reaction}

After preparation, the catalyst was characterised using $\mathrm{N}_{2}$ physisorption, $\mathrm{XRD}$, Raman scattering, inductively coupled plasma optical emission spectrometry (ICPOES), scanning electron microscopy (SEM) and transmission electron microscopy (TEM). $\quad \mathrm{N}_{2}$ physisorption measurements were performed using a Micromeritics Gemini 2370 instrument. XRD studies were performed using a Siemens D5000 diffractometer, with $\mathrm{Cu} \mathrm{K}_{\alpha}$ radiation in Bragg-Brentano geometry in the $2 \theta$ range 5$85^{\circ}$ (step size $0.02^{\circ} \mathrm{s}^{-1}$ ) using approximately $1 \mathrm{~g}$ of ground sample. Raman scattering was performed using a Horiba Jobin-Yvon LabRam HR confocal Raman microscope operating with a $532 \mathrm{~nm}$ laser source at $<20 \mathrm{~mW}$ power (measurement times approximately 5 min.). ICP-OES measurements were performed at Butterworth 
Laboratories Ltd using a Perkin Elmer Optima 7300 dual view instrument. SEM measurements were performed using a Philips XL30 ESEM equipped with an Oxford Instruments $\mathrm{x}$-act SD detector. TEM was performed using a FEI Technai T20 microscope that is equipped with a Gatan Imaging Filter and was operated at an accelerating voltage of $200 \mathrm{keV}$. Samples were ground and suspended in methanol (Sigma Aldrich, 99.8\%) before deposition on a holey carbon grid for insertion to the microscope chamber. Elemental mapping was performed by energy filtered imaging of the iron, oxygen and carbon K-edges (40, 35, $20 \mathrm{eV}$ slit widths and 728, 532, 284 eV energy levels respectively) using the Gatan image filter.

\section{Post-reaction}

After CO hydrogenation for 6 hours in the micro-reactor set-up, characterisation was performed using a combination of in situ TPO and ex situ XRD, Raman and TEM following the procedures outlined in Sections II-B and II-DI. Following INS measurements of the scaled up reacted samples, characterisation was performed using ex situ TPO, XRD, Raman and TEM. For ex situ TPO measurements, approximately $40 \mathrm{mg}$ of the reacted catalyst sample was loaded into a $1 / 4$ " diameter quartz tube reactor and attached to the micro-reactor rig described in Section II-B. Quantified carbon values obtained from the in situ TPO analysis were normalised to the mass of iron present in the sample $\left(\mathrm{g}^{-1} \mathrm{Fe}\right)$, as the mass of iron remains constant throughout the reaction measurement. However, for ex situ TPO analysis of the scaled-up reacted samples, the carbon values are normalised to the mass of sample used for the TPO study ( $\mathrm{g}^{-1}$ sample), as it is not possible to estimate with certainty the amount of iron present in the sample when taking a fraction from the scaled-up reactor for the TPO 
analysis. The XRD, Raman and TEM measurements were performed using the same equipment and procedures as outlined above.

\section{Results and discussion}

\section{A. Catalyst characterisation}

The catalyst surface area determined by $\mathrm{N}_{2}$ physisorption was $70.8 \mathrm{~m}^{2} \mathrm{~g}^{-1}$. This value significantly exceeds that of the iron oxide sample previously investigated $\left(32.1 \mathrm{~m}^{2} \mathrm{~g}^{-}\right.$ $\left.{ }^{1}\right){ }^{10,12}$ and is attributed to the greater control over the precipitation stage during the catalyst preparation that is afforded by the automated batch reactor equipment described in Section II-A. XRD analysis of the freshly prepared sample (Fig. S3) indicates the iron oxide phase to be $\alpha-\mathrm{Fe}_{2} \mathrm{O}_{3}$ (hematite) ${ }^{23}$. Application of the Scherrer equation ${ }^{24,25}$ to estimate mean crystallite size suggests a mean diameter of $c a .20 \mathrm{~nm}$. The Raman spectrum of the freshly prepared sample is presented in Fig. S4 and also indicates the sample to consist of $\alpha-\mathrm{Fe}_{2} \mathrm{O}_{3}{ }^{26}$. ICP-OES analysis of the iron oxide sample found an iron content of $65.2 \mathrm{~mol} \%$, consistent with an iron content of $\alpha$ $\mathrm{Fe}_{2} \mathrm{O}_{3}(69.9 \% \mathrm{~m} / \mathrm{m})$. The sample was also analysed for the presence of $\mathrm{Mn}, \mathrm{K}$ and Na content but, in all cases, no signal was observed indicating any possible concentration of these elements to be below the instrumental detection level of $<0.05$ mol \%. A SEM micrograph of the catalyst sample is presented in Fig. S5 and indicates the sieving procedure to have produced aggregate blocks of material within the size fraction $(250-500 \mu \mathrm{m})$. A TEM micrograph of the catalyst sample is presented in Fig. S6 and shows the micro-crystallites to exhibit an average diameter of $c a .20 \mathrm{~nm}$; in good agreement with the XRD data (Fig. S3). Figure S6 also shows the iron oxide crystallites to exhibit a narrow particle size distribution; this beneficial 
attribute is associated with the automated precipitation procedure used to make these samples. Indexing of the lattice spacing (not shown) indicates a d-spacing of 0.364 $\mathrm{nm}$, consistent with $\alpha-\mathrm{Fe}_{2} \mathrm{O}_{3}(d(012)=0.368 \mathrm{~nm})^{23}$.

\section{B. Micro-reactor studies}

The iron oxide samples were exposed to a $1: 2 \mathrm{CO} / \mathrm{H}_{2}$ mixture at $623 \mathrm{~K}$ for 6 hours, with the reaction profile presented in Fig. 1. Stages labelled I to III respectively indicate the reduction of $\alpha-\mathrm{Fe}_{2} \mathrm{O}_{3}$ towards $\mathrm{Fe}^{0}$, the formation of iron carbides and the system attaining pseudo-steady state operation. Stage I occurs during the temperature ramp of the reaction and is signified by a large peak in the $\mathrm{CO}_{2}$ trace at approximately $512 \mathrm{~K}$. Addition of the $\mathrm{CO}$ and $\mathrm{CO}_{2}$ traces during this period returns a full mass balance, suggesting $\mathrm{CO}$ consumption is stoichiometrically linked to $\mathrm{CO}_{2}$ production. Equation 3 presents the reduction of $\alpha-\mathrm{Fe}_{2} \mathrm{O}_{3}$ to $\mathrm{Fe}_{3} \mathrm{O}_{4}$ by $\mathrm{CO}$ to yield $\mathrm{CO}_{2}$, i.e. Stage I of the reaction coordinate (Fig. 1). Thereafter, further reduction proceeds towards $\mathrm{Fe}^{0}$ via $\mathrm{Fe}_{3} \mathrm{O}_{4}{ }^{27}$.

$$
\mathrm{CO}(\mathrm{g})+3 \alpha-\mathrm{Fe}_{2} \mathrm{O}_{3}(\mathrm{~s}) \rightarrow \mathrm{CO}_{2}(\mathrm{~g})+2 \mathrm{Fe}_{3} \mathrm{O}_{4}(\mathrm{~s})
$$

Stage II is characterised by the simultaneous production of $\mathrm{CO}_{2}, \mathrm{H}_{2} \mathrm{O}$ and $\mathrm{CH}_{4}$, with the consumption of $\mathrm{CO}$ peaking at $623 \mathrm{~K}$. The third stage of the reaction profile indicates the system to be reaching pseudo steady-state operation, as signified by the stabilised production of $\mathrm{CH}_{4}$ and $\mathrm{CO}_{2}$. The presence of $\mathrm{CO}_{2}$ indicates that water gas shift chemistry is occurring alongside the methanation pathway. Under these conditions CO conversion approximates to $<1 \%$, with catalytic activity 


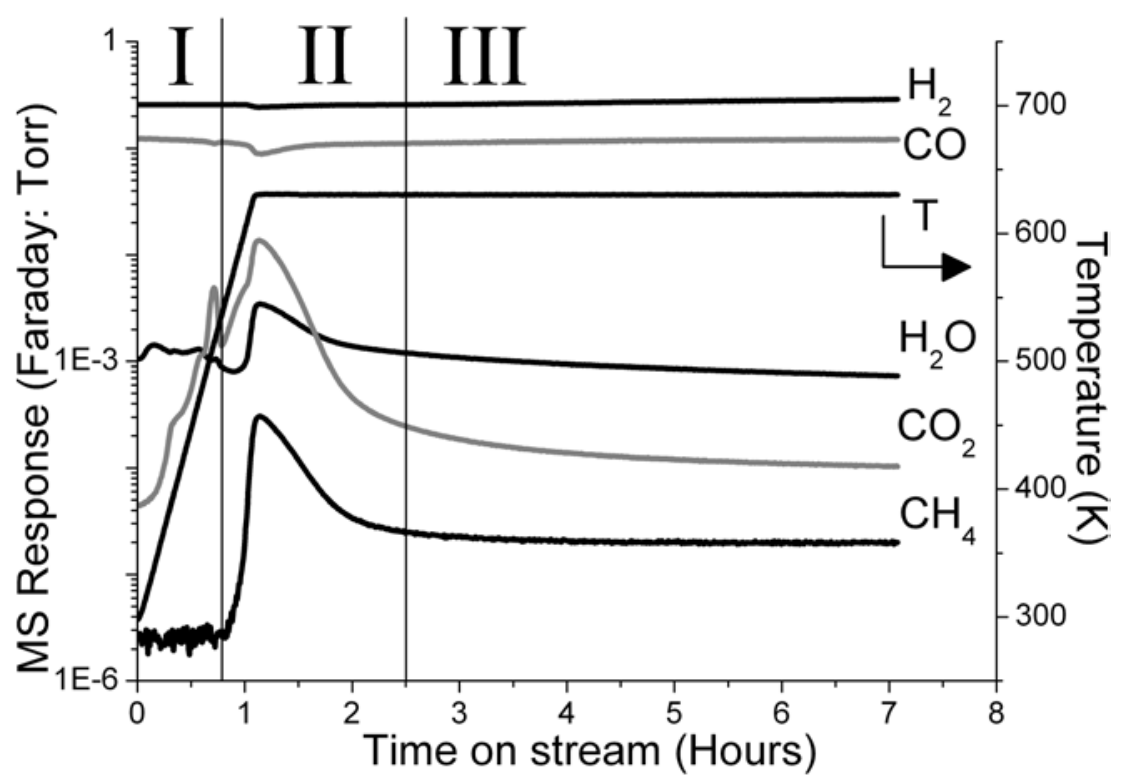

Figure 1 - The MS reaction profile for micro-reactor CO hydrogenation over the iron oxide catalyst at $623 \mathrm{~K}$ for 6 hours. The mass traces are labelled on the right hand side of the profile.

approximating to an iron time yield (FTY) of $0.01 \times 10^{-5} \mathrm{~mol} \mathrm{CO} \mathrm{g}^{-1} \mathrm{Fe} \mathrm{s} \mathrm{s}^{-1}$; a value similar to reports for bulk iron catalysts operating under comparable reaction conditions ${ }^{28}$. It is noted that this high surface area catalyst exhibits a more sustainable reaction profile at this temperature than its lower surface area equivalent described in the earlier INS studies of Hamilton et al. ${ }^{10}$.

\section{Post reaction characterisation of the micro-reactor sample}

\section{In situ temperature programmed oxidation}

After 6 hour reaction at $623 \mathrm{~K}$, the sample was cooled to room temperature and characterised using in situ TPO. Fig. 2 presents the $\mathrm{CO}_{2}$ trace produced from the oxidation of carbonaceous species present in the sample. Figure S7 presents the same TPO plot but additionally includes the trace for water $(\mathrm{m} / \mathrm{z}=18)$ and shows a minimal contribution for desorbed water. Indeed, the integrated water signal relative to the 
total $\mathrm{CO}_{2}$ signal is $<3 \%$. This indicates the dominant surface species to be predominantly carbonaceous in nature and quantification of retained carbon via TPO profiles to be a viable proposition.

Fig. 2 shows three distinct peaks ( $\alpha, \beta$ and $\gamma$ ) to be respectively present at 494, 611 and $649 \mathrm{~K}$. The carbonaceous entity connected with peak $\alpha$ at $494 \mathrm{~K}$ is tentatively associated with a reactive carbonaceous species present in the post-reaction sample. The integrated area of this feature corresponds to a carbon content of 2.78 mmoles C $\mathrm{g}^{-1}$ Fe. Peak $\beta$ at $611 \mathrm{~K}$ corresponds to 15.47 mmoles $\mathrm{C} \mathrm{g}^{-1}$ Fe. Both peaks $\alpha$ and $\beta$ are relatively sharp; indicative of a narrow distribution of carbonaceous species in each case. The final peak, $\gamma$, centred at $649 \mathrm{~K}$ is broader than the other two peaks and corresponds to 8.99 mmoles $\mathrm{C} \mathrm{g}^{-1} \mathrm{Fe}$. No desorption features are seen above $750 \mathrm{~K}$, suggesting that the retained carbon formed from $6 \mathrm{~h}$ reaction has a negligible graphitic component.

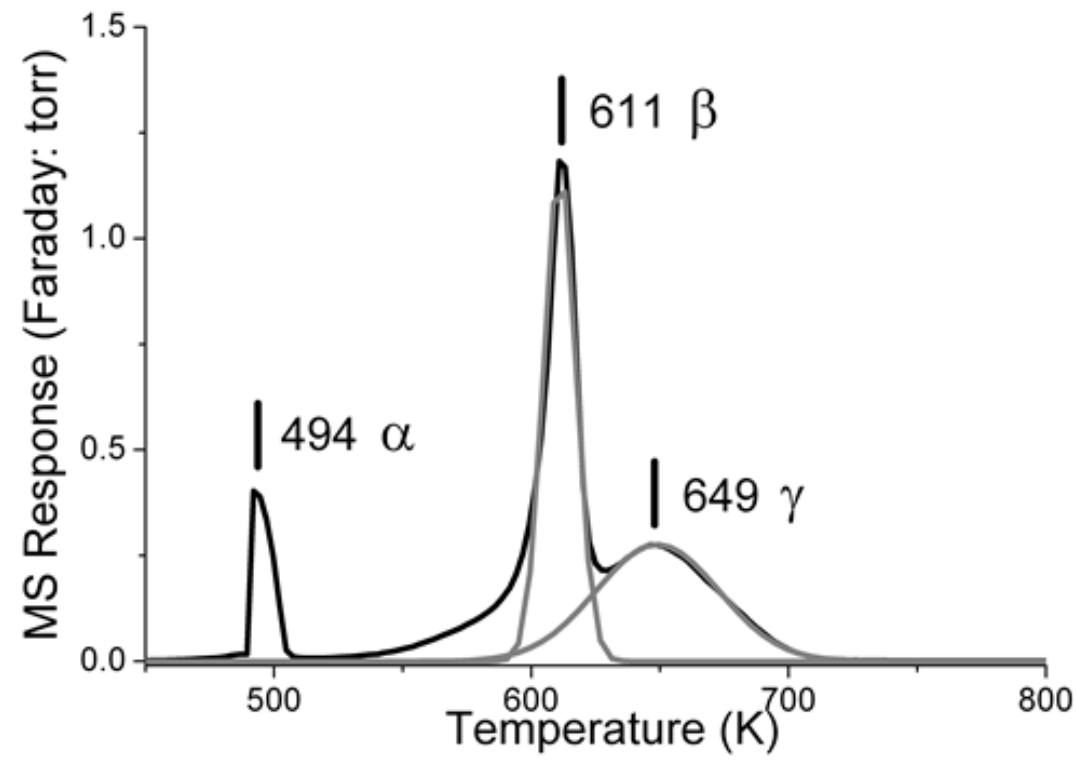

Figure 2 - The in situ temperature programmed oxidation profile of the iron oxide catalyst after 6 hours CO hydrogenation at $623 \mathrm{~K}$ in the micro-reactor arrangement. 
Several studies have employed temperature-programmed techniques to examine the reactivity of carbonaceous deposits that form on iron-based catalysts after different reaction conditions ${ }^{14,29-32}$. For example, temperature-programmed hydrogenation measurements from Bartholomew and co-workers applied to carbonaceous deposits present on a reacted silica-supported iron catalyst (538 K, $\left.10 \mathrm{bar}, \mathrm{H}_{2}: \mathrm{CO}=1\right)$ describe four groups in order of decreasing reactivity; (1) adsorbed atomic carbon, (2) amorphous/ lightly polymerised hydrocarbon or carbon surface species, (3) bulk carbides and (4) disordered/ moderately ordered graphitic surface carbon ${ }^{29}$. Further, Galuszka and co-workers' infrared spectroscopy and thermogravimetric analysis study of carbonaceous deposits on reacted oxide-supported iron catalysts (573 K, 15.15 bar, $\mathrm{H}_{2}: \mathrm{CO}=1$ ) during TPO conditions found various carbonaceous deposits to be present (aliphatic, aromatic, carbidic, amorphous and oxygenated) ${ }^{31}$. They associated species oxidised at ca. $613 \mathrm{~K}$ and below to hydrocarbonaceous material, specifically saturated oligomers and reported that all hydrocarbonaceous deposits were oxidised by $673 \mathrm{~K}^{31}$. Although these previous studies were performed on supported iron samples reacted at high pressures, the $\mathrm{CO}_{2}$ peaks in Fig. 2 could be categorised in order of decreasing reactivity as proposed by Bartholomew and coworkers $^{29}$, i.e. adsorbed atomic carbon (peak $\alpha$ ), amorphous/lightly polymerised hydrocarbon or carbon surface species (peak $\beta$ ) and bulk carbides (peak $\gamma$ ). These tentative assignments are broadly consistent with Galuszka et al.'s deductions ${ }^{31}$. This topic is discussed further and these initial assignments refined in Section III-DIII.

\section{Ex situ Powder X-ray diffraction}

The ex situ powder X-ray diffractogram of the micro-reacted iron oxide sample is presented in Fig. 3 and is characterised by a manifold of reflections between 40 and 
$50^{\circ}$ that can be attributed to iron carbides ${ }^{14,33,34}$. It is clear upon comparison with the freshly prepared catalyst diffractogram (Fig. S3) that the catalyst has been reduced from the starting iron oxide phase of $\alpha-\mathrm{Fe}_{2} \mathrm{O}_{3}$ through the processes outlined in Section III-B; namely reduction of $\alpha-\mathrm{Fe}_{2} \mathrm{O}_{3}$ to metallic iron ( $\alpha$-Fe) with the formation of iron carbides. These processes were also indicated by Stage I of the reaction profile (Fig. 1) where $\mathrm{CO}$ consumption and $\mathrm{CO}_{2}$ production were attributed to $\alpha$ $\mathrm{Fe}_{2} \mathrm{O}_{3}$ reduction. Unfortunately given the limited resolution of the diffractogram, it is not possible to assign these reflections to a specific carbide phase (Hägg carbide ( $\chi$ $\left.\mathrm{Fe}_{5} \mathrm{C}_{2}\right)$ and cementite $\left(\theta-\mathrm{Fe}_{3} \mathrm{C}\right)$ both possess similar features at $\left.c a .44 .5^{\mathrm{o} 3}{ }^{34}\right)$. Figure 3 indicates that the presence of $\alpha$-Fe is also possible, as evidenced by a small reflection at $82.5^{\circ}{ }^{35}$. Confirmation of this assertion is hindered by the main (110) reflection of $\alpha$-Fe at $44.7^{\circ}$ coinciding with the manifold of iron carbide reflections. Further, the presence of $\alpha$-Fe could be understated in Figure 3 as a consequence of the passivation procedures employed. The absence of a broad reflection at $c a .20^{\circ}$, attributable to the long-range order of amorphous carbon ${ }^{14}$ indicates that the amorphous carbon observed in the TPO study ( $\beta$ peak, Fig. 2 ) lacks the long-range crystallinity to be observed by XRD.

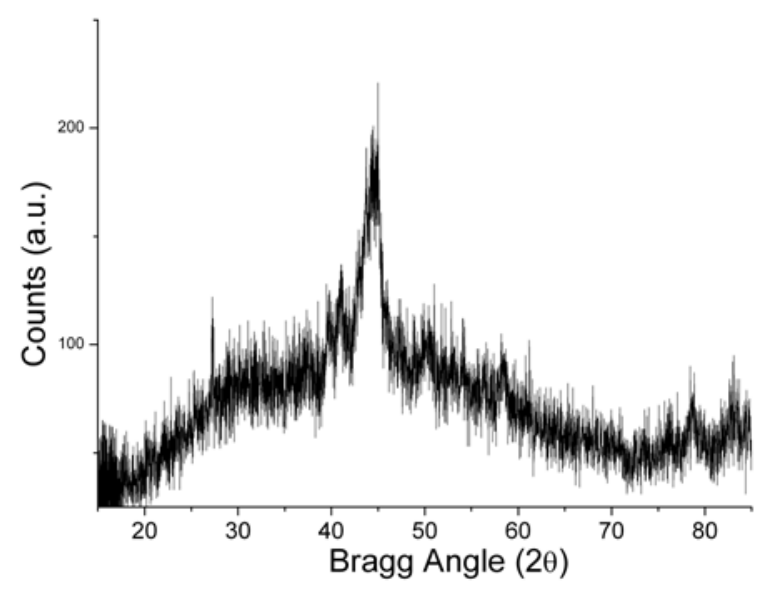

Figure 3 - The ex situ powder X-ray diffractogram of the iron oxide catalyst after 6 hours CO hydrogenation at $623 \mathrm{~K}$ in the scaled-up reactor arrangement. 


\section{Ex situ Raman spectroscopy}

The reacted catalyst sample was studied using Raman spectroscopy, with the resulting spectrum presented in Fig. 4. The spectrum is indicative of carbonaceous material: disordered carbon (D1, D4), amorphous carbon (D3) and ordered carbon (G) ${ }^{36-38}$. Curve fitting of the Raman spectrum in the region $1000-1800 \mathrm{~cm}^{-1}$ affords the following assignments: D1 $\left(1348 \mathrm{~cm}^{-1}\right)$, D3 (1508 $\left.\mathrm{cm}^{-1}\right)$, D4 $\left(1182 \mathrm{~cm}^{-1}\right)$ and G (1601 $\mathrm{cm}^{-1}$ ). The presence of the D2 band located at approximately $1620 \mathrm{~cm}^{-1}$ is understood to have a positive correlation with the D3 band ${ }^{39}$ but has not been fitted here as the peak is difficult to observe ${ }^{40}$. As with our previous studies investigating reacted iron based catalysts, the $\mathrm{G}$ band at $1601 \mathrm{~cm}^{-1}$ indicates the presence of highly ordered carbon. From the TPO (Fig. 2) and XRD (Fig. 3) results shown previously, it is clear that there is an absence of graphitic carbon in the post-reaction sample. Therefore it is proposed that the G band observed in Fig. 4 consists of short-range, highly ordered carbon that is graphitic-like in structure but lacks the long-range order to give rise to an extended network of graphitic carbon. Collectively, the TPO, XRD and Raman measurements of the post-reaction sample indicate the presence of amorphous carbon (peak $\beta$, Fig. 2 and D3 peak, Fig. 4) and iron carbides (peak $\gamma$, Fig. 2 and Fig. 3).

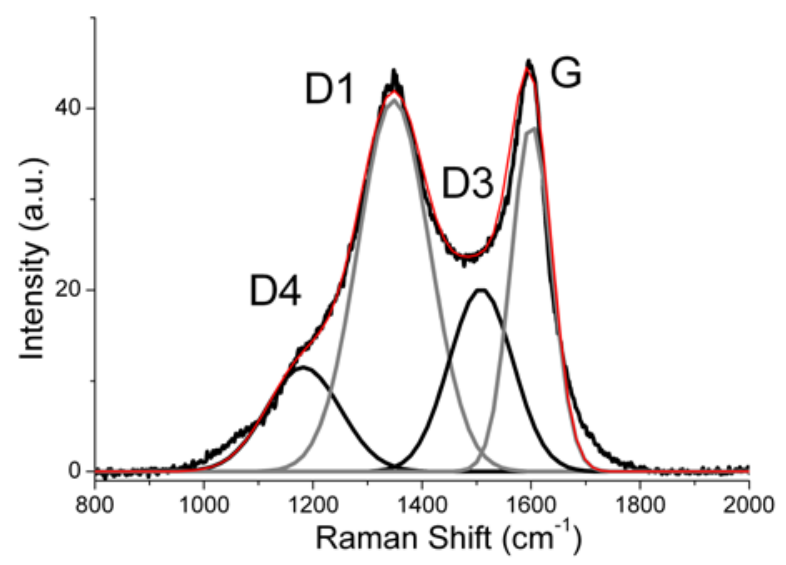

Figure 4 - The ex situ Raman spectrum of the iron oxide catalyst after 6 hours CO hydrogenation at $623 \mathrm{~K}$ in the micro-reactor arrangement. 


\section{Ex situ transmission electron microscopy}

A TEM micrograph of the reacted catalyst sample is presented in Fig. 5, which shows the sample to be characterised by a core-shell structure of a metallic, nanoparticulate core that possess an outer, less dense shell. Note also that the material is not exclusively nanoparticulate, having a substantial fraction of longer fingers of material that may have arisen from the coalescence of nanoparticles with cross-sectional dimensions in broad agreement with the $20 \mathrm{~nm}$ deduced from XRD measurements of the unreacted catalyst. The lattice planes of the central core are indexed at site $\mathbf{A}$ to be $0.57 \mathrm{~nm}$, in good agreement with monoclinic $\mathrm{Fe}_{5} \mathrm{C}_{2}(d(200)=0.572 \mathrm{~nm})$. The outer layer coating the iron carbide core is approximately $3-5 \mathrm{~nm}$ thick and is attributed to amorphous-like carbon, as identified in the TPO and Raman measurements (Fig. 2 and $\mathbf{4}$ respectively). There are some weak fringes evident in the shell material, running parallel to the nanoparticle surface. These appear consistent with a degree of graphitic ordering but do not encapsulate the core and account for a smaller fraction of the shell than in fully graphitic 'carbon onion' systems. ${ }^{50}$

A lower magnification micrograph is displayed in Fig. 6 and includes energy filtered TEM (EFTEM) elemental maps of iron, carbon and oxygen: Fig. 6(b), (c) and (d) respectively, where increased white contrast corresponds to an increase in concentration of the particular element. Fig. 6(a) is the 'parent', zero-energy loss micrograph. 


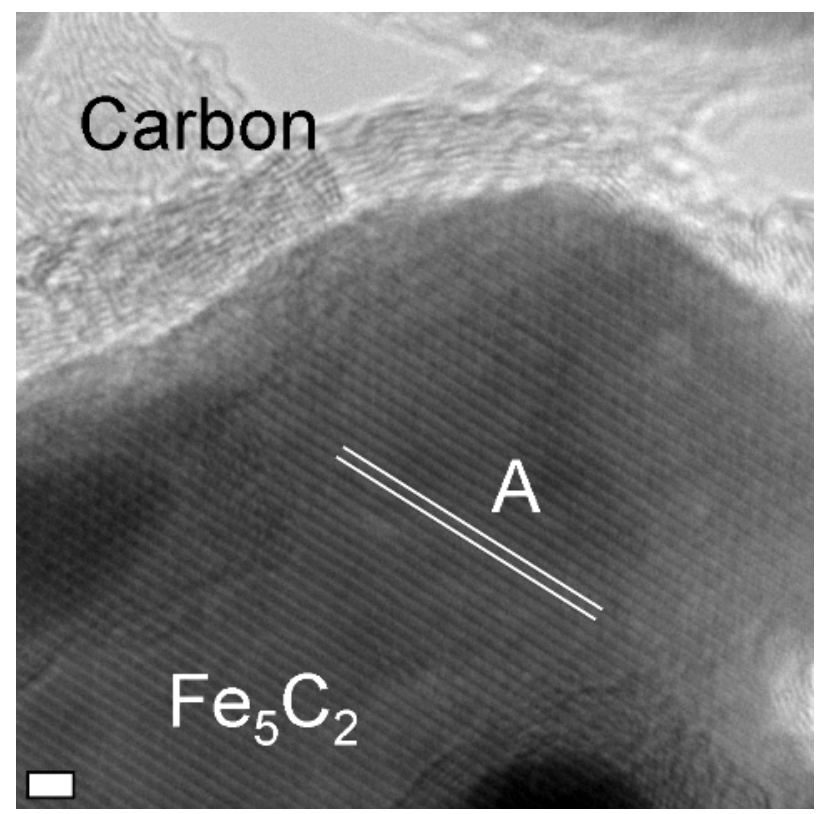

Figure 5 - HRTEM of the iron oxide catalyst after 6 hours CO hydrogenation at $623 \mathrm{~K}$ in the micro-reactor arrangement. The $d$-spacing marked by $A$ is $0.57 \mathrm{~nm}$, characteristic of monoclinic $\mathrm{Fe}_{5} \mathrm{C}_{2}$. The white scale bar represents $\mathbf{2} \mathbf{~ n m}$.

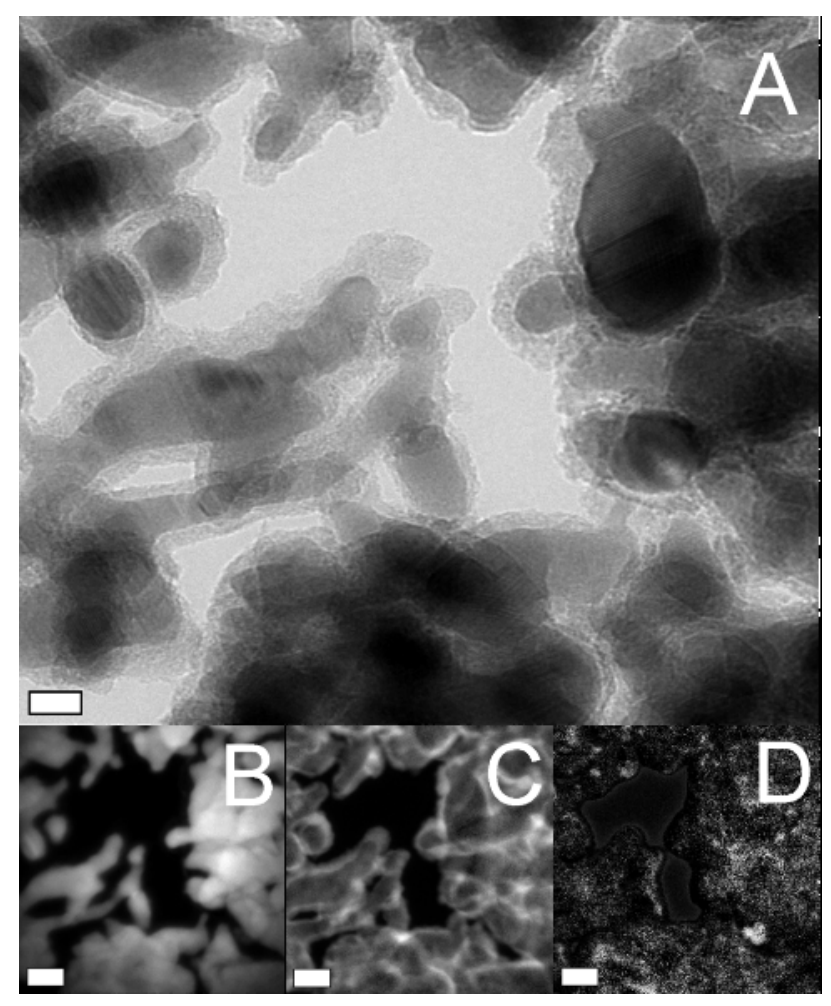

Figure 6 - Ex situ energy filtered TEM images of the iron oxide catalyst after 6 hours CO hydrogenation at $623 \mathrm{~K}$ in the micro-reactor arrangement. A - Energy 
filtered, zero-energy loss micrograph (i.e. bright field), scale bar represents 10 nm; B - iron map based on the intensity of the $L_{2,3}$ energy loss feature, scale bar represents $20 \mathrm{~nm}$; C - carbon map based on $\mathrm{K}$ shell energy loss, scale bar represents $20 \mathrm{~nm}$; D - oxygen map, based on the $\mathrm{K}$ shell energy loss, scale bar represents $20 \mathrm{~nm}$.

Fig. 6(b) shows that iron corresponds to the darkest (denser) material in the bright field images and is predominately found within the inner core of the particles, whilst Fig. 6(c) shows that carbon mainly occupies the outer layers. Carbon intensity is clear throughout the material but it is not simple to distinguish between carbon dissolved in the iron and the carbon coating, since the image is a two-dimensional projection of the three-dimensional material. The oxygen map (Fig. 6(d)) is rather sparse, but does seem to correlate with the carbonaceous shell, with small pockets of oxygen found in the inner cores of some of the smaller Fe-rich particles, suggesting the presence of residual iron oxide material (e.g. magnetite) in the reacted catalyst. Fig. 6 provides a vivid illustration of the components that comprise the active phase of the catalyst under investigation.

\section{Inelastic neutron scattering measurements}

\section{Scaled up reaction testing}

Before analysis by INS, the catalyst experienced CO hydrogenation at $623 \mathrm{~K}$ for 6 hours using the catalyst preparation apparatus described in Section II-C ${ }^{20}$. The reaction profile for CO hydrogenation over the dehydrated catalyst is presented in Fig. 7. As the mass spectrometer at the Central Facility was not calibrated for gas response factors, Fig. 7 provides a qualitative description of the reaction profile. 


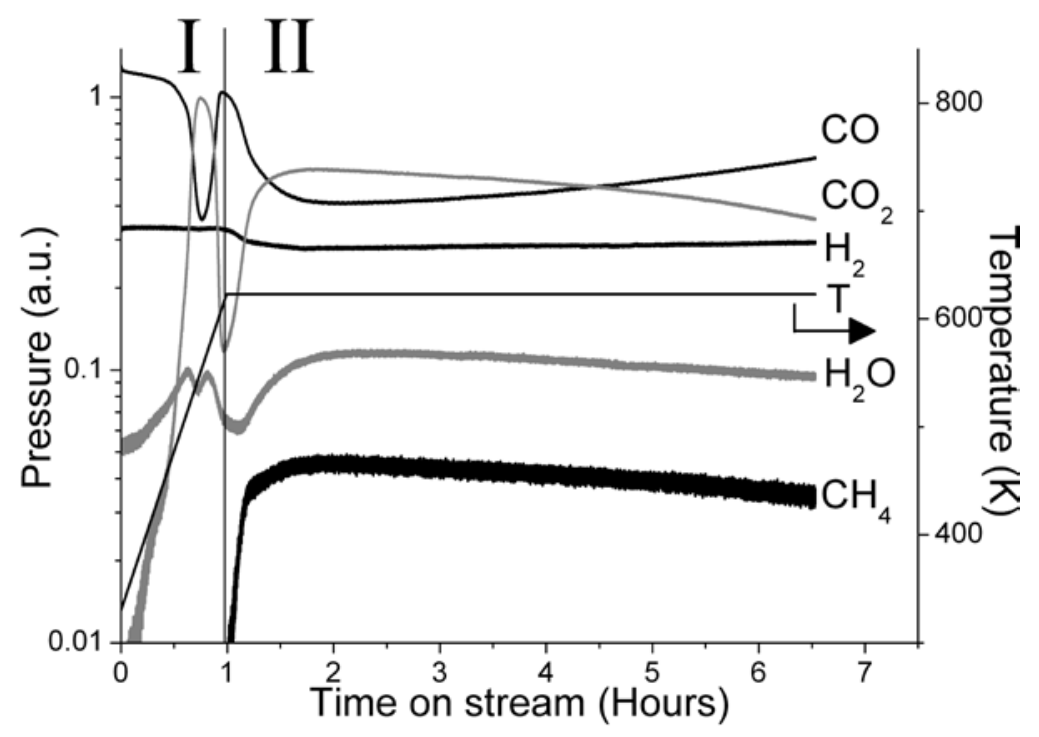

Figure 7 - The MS reaction profile for scaled up CO hydrogenation over the iron oxide catalyst at $623 \mathrm{~K}$ for 6 hours. The mass traces are labelled on the right hand side of the profile.

The profile presented in Fig. 7 can be sub-divided in to two stages: Stage I is represented by a large $\mathrm{CO}_{2}$ peak at $558 \mathrm{~K}$; Stage II/III is defined by the simultaneous production of $\mathrm{CO}_{2}$ and $\mathrm{CH}_{4}$ once the reaction temperature of $623 \mathrm{~K}$ is attained. The water signal within Stage 1 exhibits two maxima; this is thought to reflect a hydrogen contribution to the stepwise reduction of the $\alpha-\mathrm{Fe}_{2} \mathrm{O}_{3}$. It is noted that Stage $\mathrm{I}$ in the INS reactor is prolonged compared to the micro-reactor profile (Fig. 1), and this is attributed to the greater catalyst mass $(10 \mathrm{~g} c f .40 \mathrm{mg})$ requiring more time to reduce the $\mathrm{Fe}_{3} \mathrm{O}_{4}$ phase. Under these conditions, Stage II is undefined and, after ca. 2 hours on stream, the continuous methane production is thought to indicate attainment of a pseudo steady-state regime. Thus, although differences in the gas/solid exchange dynamics of the micro-reactor and the larger INS reactor are evident, the INS sample is displaying a broadly comparable reaction profile to that defined in the laboratory based measurements. After activation, and in both cases, (i) the hydrogenation of CO 
to produce methane and (ii) water gas shift chemistry to produce $\mathrm{CO}_{2}$ are the dominant chemical transformation over this catalyst at this temperature.

\section{Inelastic neutron scattering}

Fig. 8 presents the INS spectra recorded at an incident energy of $4840 \mathrm{~cm}^{-1}$. Fig. 8(a) shows the spectrum of the unreacted hematite $\left(\alpha-\mathrm{Fe}_{2} \mathrm{O}_{3}\right)$ pre-catalyst after dehydration for 3 hours and Fig. 8(b) shows the same catalyst after experiencing CO hydrogenation for 6 hours at $623 \mathrm{~K}$. The dehydrated catalyst spectrum (Fig. 8(a)) is effectively featureless, which is in dramatic contrast to the spectrum reported for the hematite pre-catalyst prepared using manual methods which displays a strong $v(\mathrm{O}-\mathrm{H})$ band corresponding to surface hydroxyl groups ${ }^{10}$. INS spectroscopy is readily able to distinguish how different preparative methods can affect hydroxyl populations at the catalyst surface. For the high surface area hematite sample under examination here, Fig. 8(b) demonstrates that the improved catalyst preparation process outlined in Section II-A leads to a negligible population of surface hydroxyl groups.

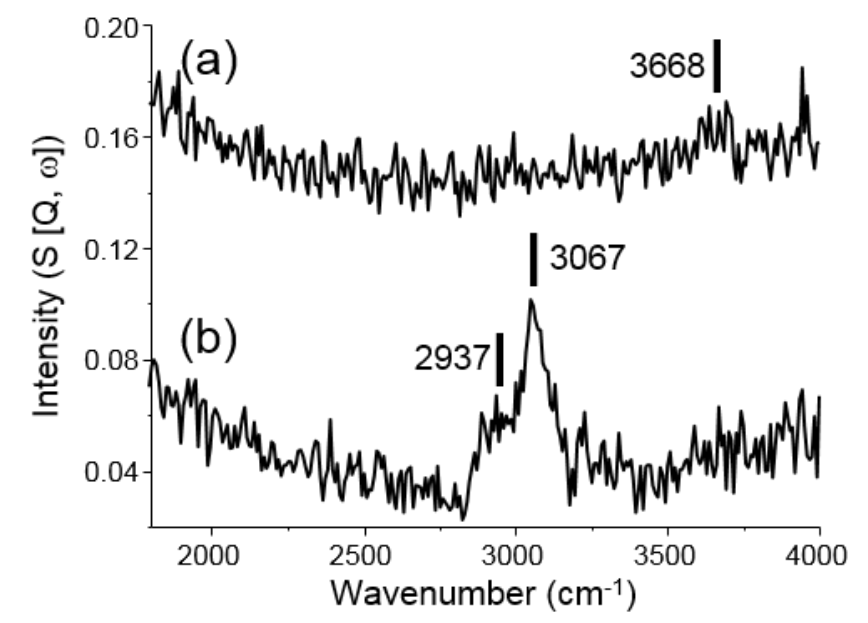

Figure 8 - The INS spectrum recorded at an incident energy of $4840 \mathrm{~cm}^{-1}$ of the scaled up iron catalyst after (a) dehydrating conditions at $373 \mathrm{~K}$ and (b) CO hydrogenation conditions at $623 \mathrm{~K}$ for 6 hours. The figure is a modified version 
of Figure 6 of reference 20 that is presented with permission from the Institute of Physics.

Fig. 8(b) shows the spectrum of the reacted sample, which is characterised by a sharp feature at $3067 \mathrm{~cm}^{-1}$ and a low energy shoulder at $2937 \mathrm{~cm}^{-1}$. These features can be assigned to $v(\mathrm{C}-\mathrm{H})$ modes: $\mathrm{sp}^{2}$ hybridised carbon, i.e. aromatic/olefinic $v(\mathrm{C}-\mathrm{H})$, at $3067 \mathrm{~cm}^{-1}$ and $\mathrm{sp}^{3}$ hybridised carbon, i.e. aliphatic $v(\mathrm{C}-\mathrm{H})$, at $2937 \mathrm{~cm}^{-1} 10,11$.

INS spectra of the pre-reaction and post-reaction catalyst samples recorded at an incident energy of $1613 \mathrm{~cm}^{-1}$ are presented in Fig. 9. The spectrum of the dehydrated sample (Fig. 9(a)) is characterised by two features located at $649 \mathrm{~cm}^{-1}$ and $810 \mathrm{~cm}^{-1}$. The feature at $649 \mathrm{~cm}^{-1}$ is tentatively ascribed to the Fe-O phonon mode of the $\alpha$ $\mathrm{Fe}_{2} \mathrm{O}_{3}$ starting material ${ }^{41}$. The $810 \mathrm{~cm}^{-1}$ peak connects with the relatively sharp peak reported at $806 \mathrm{~cm}^{-1}$ by Hamilton et al. for the INS spectrum of the as-received hematite sample prepared by manual methods ${ }^{10}$. Although Hamilton et al. tentatively assign the band to a magnetic transition, specifically a magnon feature of $\alpha-\mathrm{Fe}_{2} \mathrm{O}_{3}$ (subsequently referred to here as a spinon), the confidence in that assignment was compromised by the possibility of the band representing a partner $\mathrm{OH}$ deformation mode, $\left(\gamma(\mathrm{O}-\mathrm{H})\right.$, of an $\mathrm{O}-\mathrm{H}$ stretch observed at $3442 \mathrm{~cm}^{-1}{ }^{10}$. The absence of $v(\mathrm{O}-\mathrm{H})$ features in Fig. 9(a) categorically eliminates the possibility that the $810 \mathrm{~cm}^{-1}$ band has hydroxyl origins, thereby verifying the assignment of Hamilton et al. This topic will be examined more comprehensively in Section IV. 


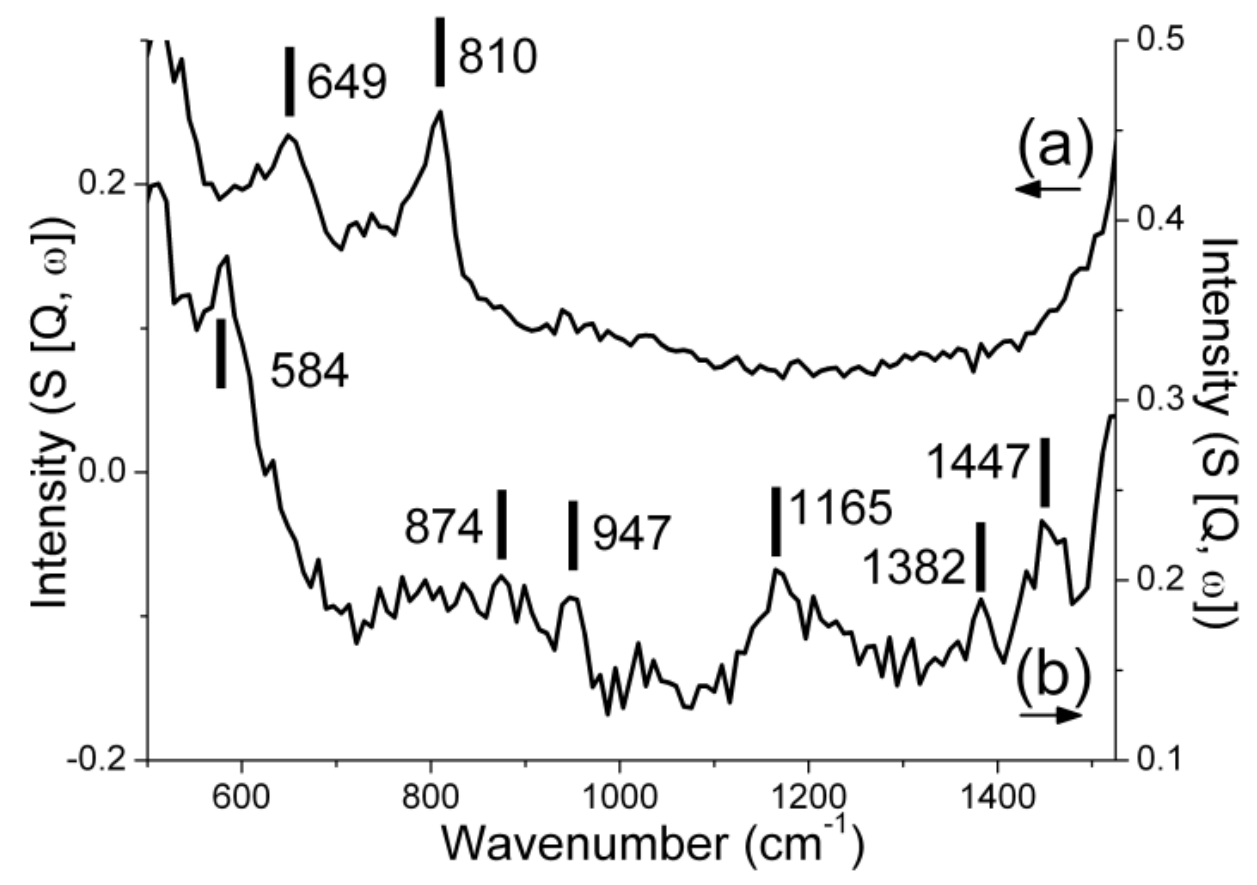

Figure 9 - The INS spectra recorded at an incident energy of $1613 \mathrm{~cm}^{-1}$ of the scaled up iron catalyst after (a) dehydrating conditions at $373 \mathrm{~K}$ and (b) CO hydrogenation conditions at $623 \mathrm{~K}$ for 6 hours.

The reacted catalyst spectrum (Fig. 9(b)) resembles spectra for reacted iron catalyst samples from our previous studies ${ }^{10,11}$. The spectrum is characterised by bands centred at 1447, 1362, 1165, 947, 874 and $584 \mathrm{~cm}^{-1}$. Assignment of these features follows from our previous studies. The $1447 \mathrm{~cm}^{-1}$ band is assigned to semi-circle ring deformation modes that are possibly linked with a $\delta(\mathrm{CH})$ mode associated with perimeter carbons of an extended polycyclic aromatic network. The weak $1362 \mathrm{~cm}^{-1}$ feature is assigned to an in-plane ring deformation of a naphthalene type molecule and the $1165 \mathrm{~cm}^{-1}$ band is assigned to a CC-H in-plane deformation mode of a polyaromatic hydrocarbon. The feature at $947 \mathrm{~cm}^{-1}$ is assigned to alkenic $\delta(\mathrm{C}-\mathrm{H})$. The band just discernible at $874 \mathrm{~cm}^{-1}$ is assigned to an out-of-plane $\mathrm{CH}$ deformation of either an olefinic or aromatic group. This feature is most likely the counterpart mode for the $v(\mathrm{C}-\mathrm{H})$ feature apparent in Fig. 8(b) at $3067 \mathrm{~cm}^{-1}$. The feature at 584 
$\mathrm{cm}^{-1}$ is tentatively assigned to the $\mathrm{A}_{1 \mathrm{~g}} \mathrm{Fe}-\mathrm{O}$ phonon mode of $\mathrm{Fe}_{3} \mathrm{O}_{4}$; consistent with the TEM observations (Section 3.3.3). Overall, these assignments show the presence of a predominantly olefinic/aromatic hydrocarbonaceous overlayer, which additionally possesses some aliphatic character, as demonstrated by the $v(\mathrm{C}-\mathrm{H})$ mode observed at $2937 \mathrm{~cm}^{-1}$.

Importantly, on comparing the low energy spectra of Fig. 9, it is evident that the 810 $\mathrm{cm}^{-1}$ of Fig. 9(a), assigned above to a spinon feature of $\alpha-\mathrm{Fe}_{2} \mathrm{O}_{3}$, is absent in the spectrum of the reacted sample (Fig. 9(b)). This is consistent with the solid matrix responsible for sustained methane production, as evidenced by Fig. 1 and 7, losing the structural and electronic characteristics connected with this specific magnetic transition.

\section{Ex situ characterisation of reacted samples after INS measurement}

Fig. 10 presents the ex situ XRD diffractogram for the reacted catalyst sample and is signified by the presence of iron carbides $\left(40-50^{\circ}\right)$ and the small presence of $\mathrm{Fe}_{3} \mathrm{O}_{4}$. Upon comparison of Fig. 10 to the ex situ XRD data from our previous studies of samples reacted at $623 \mathrm{~K}^{10,11}$, it is clear that Fig. 10 contains substantially more carbide. Residual iron oxide is also present, that can be ascribed to $\mathrm{Fe}_{3} \mathrm{O}_{4}\left(30.3^{\circ}\right.$, $35.7^{\circ}, 57.2^{\circ}, 62.8^{\circ}$ and $\left.78.8^{\circ}\right)^{35,42}$. There is also a small indication at $82.9^{\circ}$ of the presence of metallic iron ${ }^{35}$. As discussed above (Section 3.3.2), it is presumed that under reaction conditions there may be a higher presence of metallic iron. The ex situ Raman spectrum of the scaled-up reacted catalyst sample after INS measurement is presented in Fig. S8. As with the Raman spectrum of the micro-reactor sample (Fig. 
4), the spectrum is dominated by the D and G bands assigned to disordered and ordered carbon respectively.

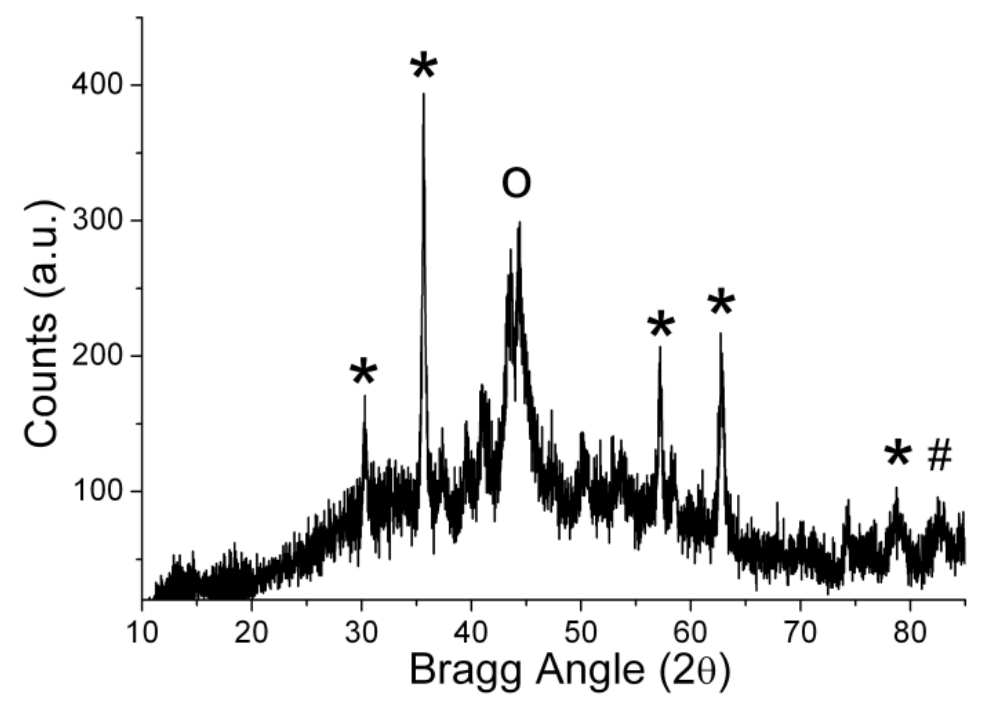

Figure 10 - The ex situ powder X-ray diffractogram of the iron oxide catalyst after 6 hours CO hydrogenation at $623 \mathrm{~K}$ in the scaled-up reactor arrangement. The asterisks indicate $\mathrm{Fe}_{3} \mathrm{O}_{4}$, the circle iron carbides and the hash tag metallic iron.

Fig. 11 presents the MS profile for the $\mathrm{CO}_{2}$ trace during the post-reaction TPO measurement. As seen with the micro-reacted sample (Fig. 2), the TPO profile consists of 3 discrete peaks: $\alpha, \beta$ and $\gamma$ centred at 482, 595 and $629 \mathrm{~K}$ respectively. The shape and position of these peaks are similar to the micro-reacted sample, suggesting that the carbonaceous deposits formed in the scaled-up reactor are similar in composition. Fig. S9 shows the water trace included alongside the $\mathrm{CO}_{2}$ profile reported in Figure 11 and, as seen for the micro-reactor data, a minimal water contribution to the overall profile is observed, validating quantification of retained carbonaceous species via post-reaction TPO measurements. 
Peak $\alpha$ is surprisingly sharp and corresponds to a carbon content of 1.15 mmoles $\mathrm{C} \mathrm{g}^{-}$ ${ }^{1}$ sample. The $\beta$ and $\gamma$ peaks in Fig. 11 are not as distinct as observed with the microreacted sample (Fig. 2) but they are still noticeably present; both peaks have been fitted in Fig. 11 for clarity. Peaks $\beta$ and $\gamma$ correspond to respective carbon concentrations of 7.83 and 3.10 mmoles $\mathrm{C} \mathrm{g}^{-1}$ sample. These values are lower than the comparative peaks in Fig. 2. It is possible that the lesser degree of carbon deposition associated with the INS sample simply reflects a retarded rate of reaction relative to the more dynamic micro-reactor arrangement.

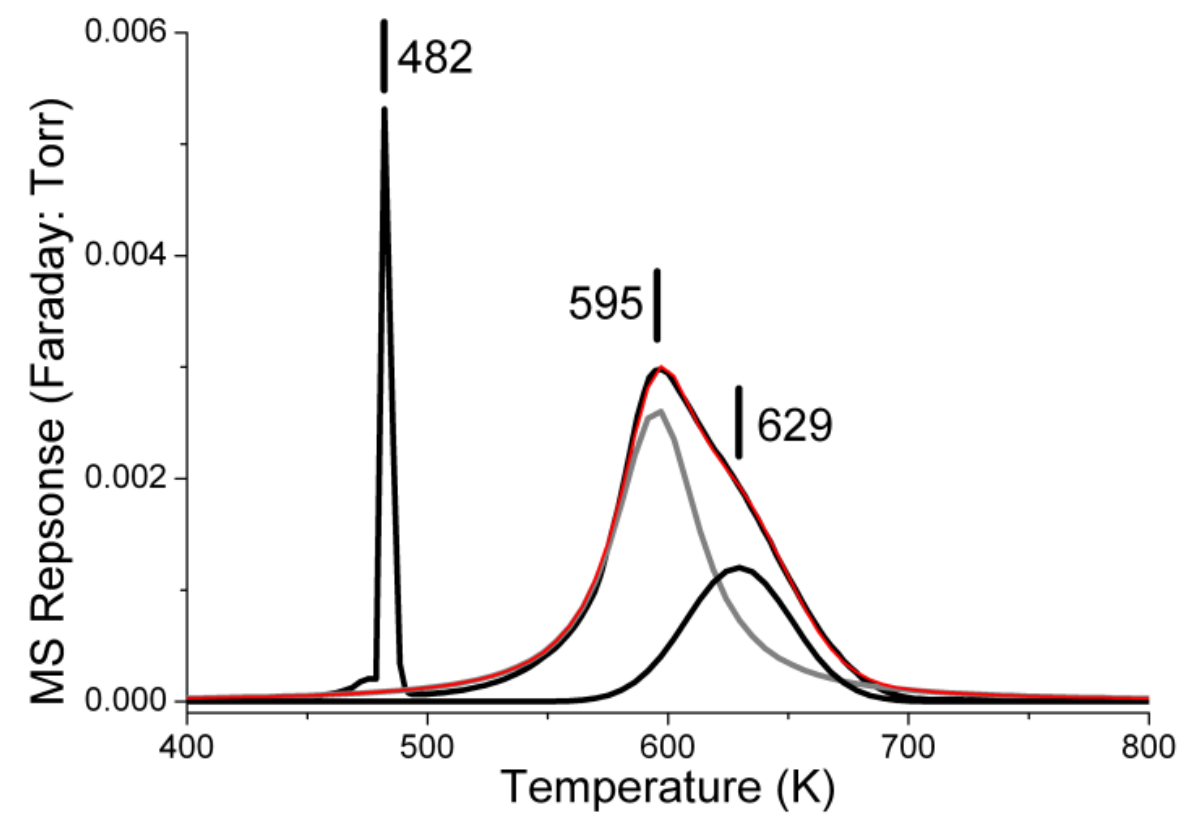

Figure 11 - The ex situ temperature programmed oxidation profile of the iron oxide catalyst after 6 hours CO hydrogenation at $623 \mathrm{~K}$ in the scaled-up reactor arrangement. The profile is fitted by a combination of Lorentzian and Gaussian line shapes.

The relatively weak scattering intensity of the INS spectra in Fig. 8(b) and 9(b) indicate a low degree of hydrogen retention as a consequence of the sustained CO turnover (Fig. 7). Thus, the quantity of the hydrocarbonaceous overlayer at the 
catalyst surface is low and it is a minority species compared to, firstly, amorphous carbon, as evidenced by TEM and Raman scattering, and secondly, to iron carbides, as evidenced by XRD and TEM. This then suggests that the hydrocarbonaceous species will have a minimal contribution to TPO profiles of retained carbonaceous entities, as evidenced in Fig. S7 and S8. Thus, hydrocarbonaceous species are excluded from assignments of the TPO profiles. In this way, the assignments for peaks $\alpha, \beta$ and $\gamma$ are refined to the following: peaks $\alpha$ - reactive carbon species formed from the dissociation of CO; peak $\beta$ - amorphous carbon; peak $\gamma$ - iron carbide.

\section{Discussion}

The INS spectra presented in Fig. 8(b) and 9(b) indicate that, after exposure to CO hydrogenation conditions for 6 hours at $623 \mathrm{~K}$, there is a small retention of hydrocarbonaceous material. The spectra are broadly similar to those reported previously for a manually prepared iron based FTS catalyst ${ }^{10}$ and, similarly, may be assigned to a population of partially hydrogenated polyaromatic molecules. These observations suggest that the presence of a hydrocarbonaceous overlayer is inherently associated with $\mathrm{CO} / \mathrm{H}_{2}$ reaction chemistry over iron based FTS catalysts. ${ }^{11}$ However, it is noted that the new catalyst preparation procedure has induced some changes to the INS spectrum. Namely, for the manually prepared iron oxide catalyst studied previously, the 6 hours / $623 \mathrm{~K}$ sample was of a predominantly aliphatic nature (and could not sustain methanation activity) [Figures 5(b) and 6(b) in reference 10], whereas the presence of unsaturated $\mathrm{C}-\mathrm{H}$ modes was only induced by 6 hours reaction at $723 \mathrm{~K}$ [Figures 5(c) and 6(c) in reference 10]. The fact that the high surface area sample under consideration in this work reacted at $623 \mathrm{~K}$ can sustain methanation 
activity and exhibits an INS spectrum consistent with a population of partially hydrogenated polyaromatic molecules suggests that, for comparable conditions of temperature and time-on-stream, the reaction coordinate is more advanced with this high surface area hematite sample.

In Section III-DII, and on the basis of no hydroxyl contributions, the relatively intense band at $810 \mathrm{~cm}^{-1}$ in Fig. 9(a) is confirmed as originating from a spinon feature of $\alpha-\mathrm{Fe}_{2} \mathrm{O}_{3}$. A spinon is a collective excitation of the spins that comprise the magnetic sublattice ${ }^{43}$, which in the case of $\alpha-\mathrm{Fe}_{2} \mathrm{O}_{3}$ consists of antiferromagnetically aligned iron ions. As a result of the magnetic moment of the neutron, INS has the capability to probe the magnetic properties of materials ${ }^{43}$, and the measurement of spin waves is standard on the MARI spectrometer ${ }^{44}$. Further, magnetism in $\alpha-\mathrm{Fe}_{2} \mathrm{O}_{3}$ is known to exhibit a crystallite size dependence, where crystallites of the order of $20 \mathrm{~nm}$ and less possess weak ferromagnetism to temperatures as low as $5 \mathrm{~K}^{45,46}$, whereas bulk $\alpha$ $\mathrm{Fe}_{2} \mathrm{O}_{3}$ is antiferromagnetic at these temperatures. As Section 3.1 shows, TEM measurements and XRD derived deductions indicate a mean hematite crystallite particle size of $c a .20 \mathrm{~nm}$. However, the finite size effects on spin excitations reported in the literature only affect the very low energy, $<40 \mathrm{~cm}^{-1}$ dynamics, which are not accessed in the INS measurements presented here.

As mentioned in the Introduction, simultaneous determination of both energy and momentum exchange during the scattering process is possible with MARI. This twodimensional spectroscopy may be presented in the form of a 'mitre plot', where neutron scattering intensity is correlated with energy transfer $\left(\omega, \mathrm{cm}^{-1}\right)$ and momentum transfer $\left(Q, \AA^{-1}\right)$. Fig. 12 presents mitre plots for the dehydrated iron 
oxide sample and the reacted sample. Fig. 12(a) presents the 2-dimensional INS spectrum of the dehydrated pre-catalyst recorded at an incident energy of $1613 \mathrm{~cm}^{-1}$. In fact, it is the integrated neutron scattering intensity over the full range of $Q$ correlated with energy transfer that yields the INS spectrum presented in Fig. 9(a). The $810 \mathrm{~cm}^{-1}$ band of Fig. 9(a) is evident in Fig, 12(a) at low Q but its intensity is observed to rapidly diminish with increasing Q.

The first spectroscopic observation of the spinon of $\alpha-\mathrm{Fe}_{2} \mathrm{O}_{3}$ was by Samuelsen and Shirane who investigated spin waves and magnetic interactions in $\alpha-\mathrm{Fe}_{2} \mathrm{O}_{3}$ single crystals using INS ${ }^{47}$. Detailed calculations of the spin wave dispersion ${ }^{47,48}$ have been shown to agree well with experimental observations, in particular the presence of two bands of spin waves. Using these calculations we are able to compute the powderaveraged spin wave dispersion, that was measured here, with a high degree of accuracy (see Fig. 12(b)) and we achieve excellent agreement with our observations. The peak of intensity near $810 \mathrm{~cm}^{-1}$ arises from a peak in the density of states of spin waves at this energy, which corresponds to the energy of the almost flat optic branch and also the Brillouin zone boundary energy of the acoustic branch.

The intensity of the $810 \mathrm{~cm}^{-1}$ band reduces rapidly with increasing Q. This is due to the magnetic form factor ${ }^{49}$ which acts as an envelope function on the intensity. Physically, it is the Fourier transform of the magnetic potential seen by the neutron. Because the magnetic potential is very long range, its Fourier transform is peaked at low $\mathrm{Q}$ and decays quickly. This is the opposite of the nuclear potential, which is very short range, so its Fourier transform is almost Q-independent. Our calculation (Fig. 
12(b)) incorporated the iron magnetic form factor, and the reduction of intensity with increased Q is correctly reproduced.

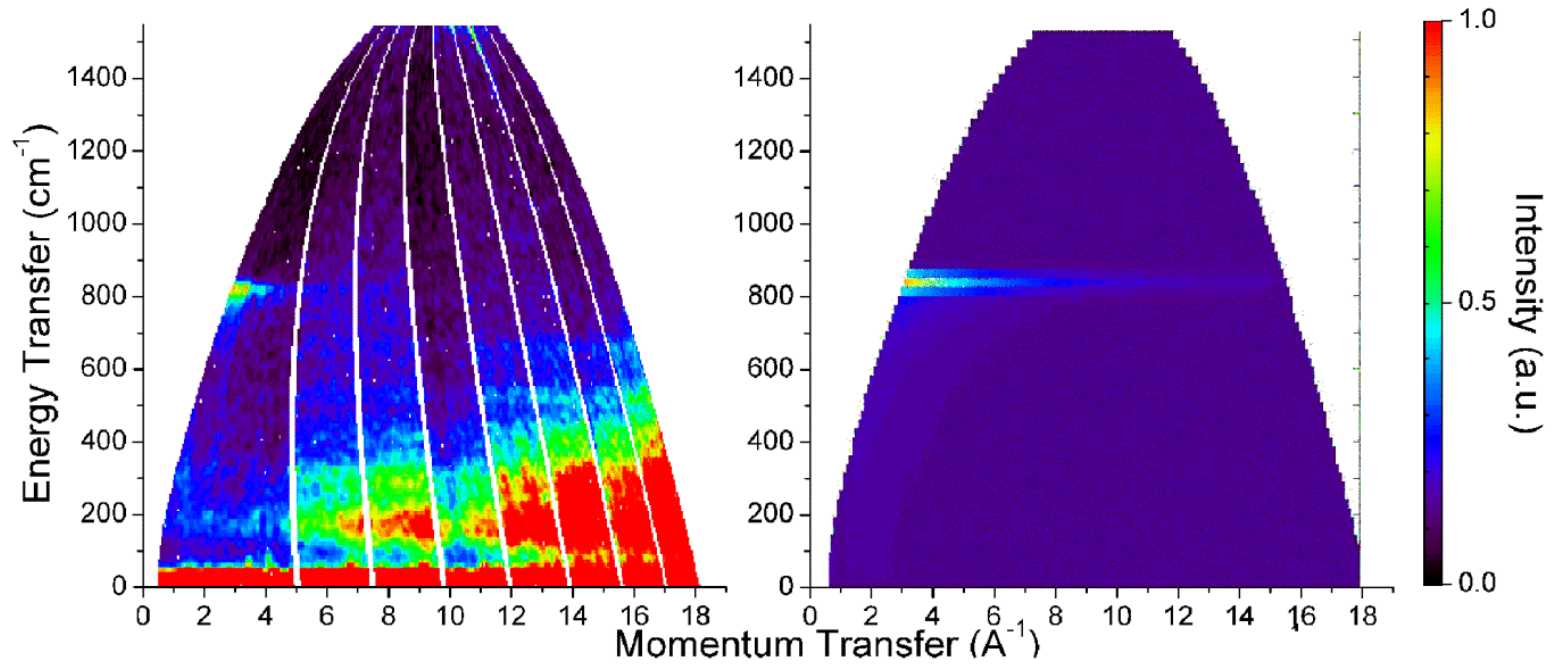

Figure 12 -Comparison of neutron scattering intensity as a function of energy and momentum transfer (mitre plots) for the iron oxide catalyst after (a) dehydrating conditions at $373 \mathrm{~K}$, recorded at an incident energy of $1613 \mathrm{~cm}^{-1}$, and (b) the simulated powder-averaged spin wave dispersion of $\alpha-\mathrm{Fe}_{2} \mathrm{O}_{3}$.

The mitre plot for the reacted sample recorded at an incident energy of $4840 \mathrm{~cm}^{-1}$ is shown in Fig. 13. In a similar manner to that described above, correlation of neutron scattering intensity summed over all values of $Q$ and correlated against energy transfer yields the 1-dimensional INS spectrum shown in Fig. 8(b). A weak feature is discernible about $3000 \mathrm{~cm}^{-1}$ that possesses intensity out to Q values of ca. $20 \AA^{-1}$. This scattering intensity corresponds to the $v(\mathrm{C}-\mathrm{H})$ modes of Fig. 8(b). 


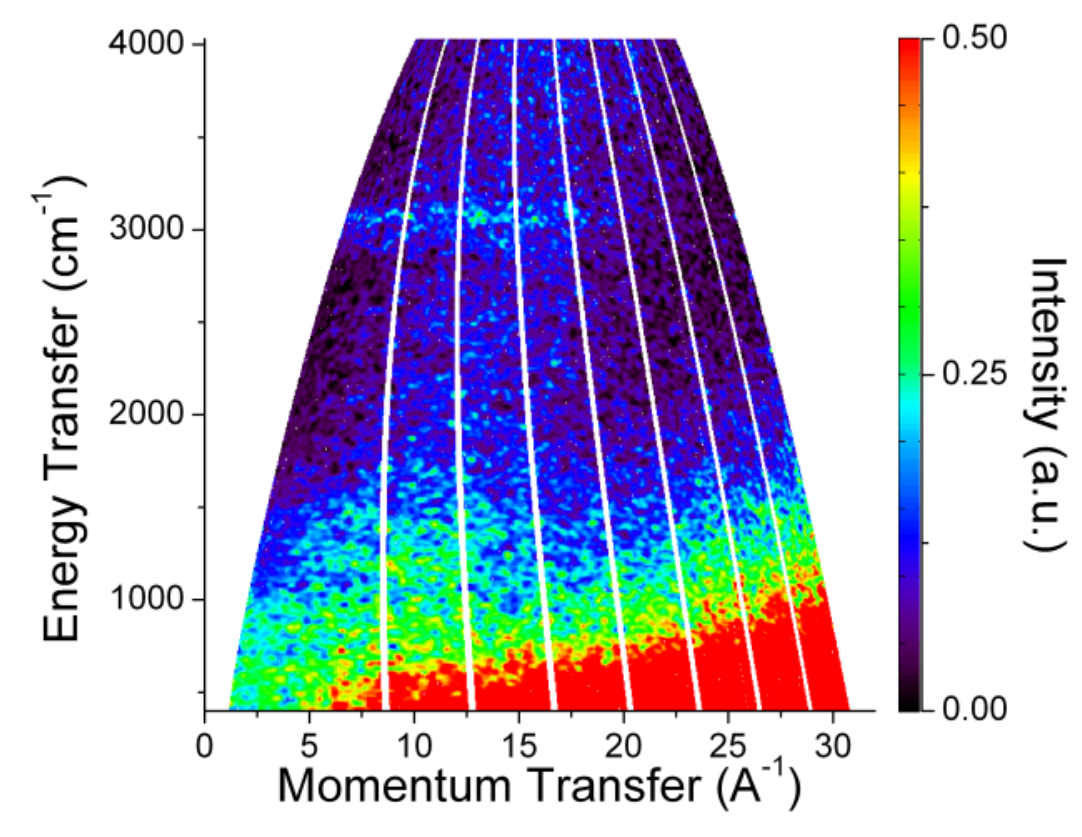

Figure 13 - Mitre plot for the iron oxide catalyst after CO hydrogenation conditions at $623 \mathrm{~K}$ for 6 hours, recorded with an incident energy of $4840 \mathrm{~cm}^{-1}$.

Fig. 14 compares the energy transfer versus momentum transfer dependencies for the transition observed at $810 \mathrm{~cm}^{-1}$ in Fig. 9(a) and the $v(\mathrm{C}-\mathrm{H})$ modes observed about $3000 \mathrm{~cm}^{-1}$ in Fig. 8(b). The difference between the two profiles is dramatic. Neutron scattering intensity for the $810 \mathrm{~cm}^{-1}$ band of the bulk iron oxide pre-catalyst, Fig. 14(a), decreases sharply upon increasing Q; categorically confirming a nuclear spin interaction for this mode ${ }^{49}$. Our calculation of the Q-dependence of the $\alpha-\mathrm{Fe}_{2} \mathrm{O}_{3}$ spinon is shown in Fig. 12(d) and is in agreement with the experimental observation. By way of contrast, the neutron scattering intensity of the $v(\mathrm{C}-\mathrm{H})$ modes indicative of the hydrocarbonaceous overlayer of the reacted catalyst, Fig. 14(b), is weaker and displays a maximum at approximately $15 \AA^{-1}$. 


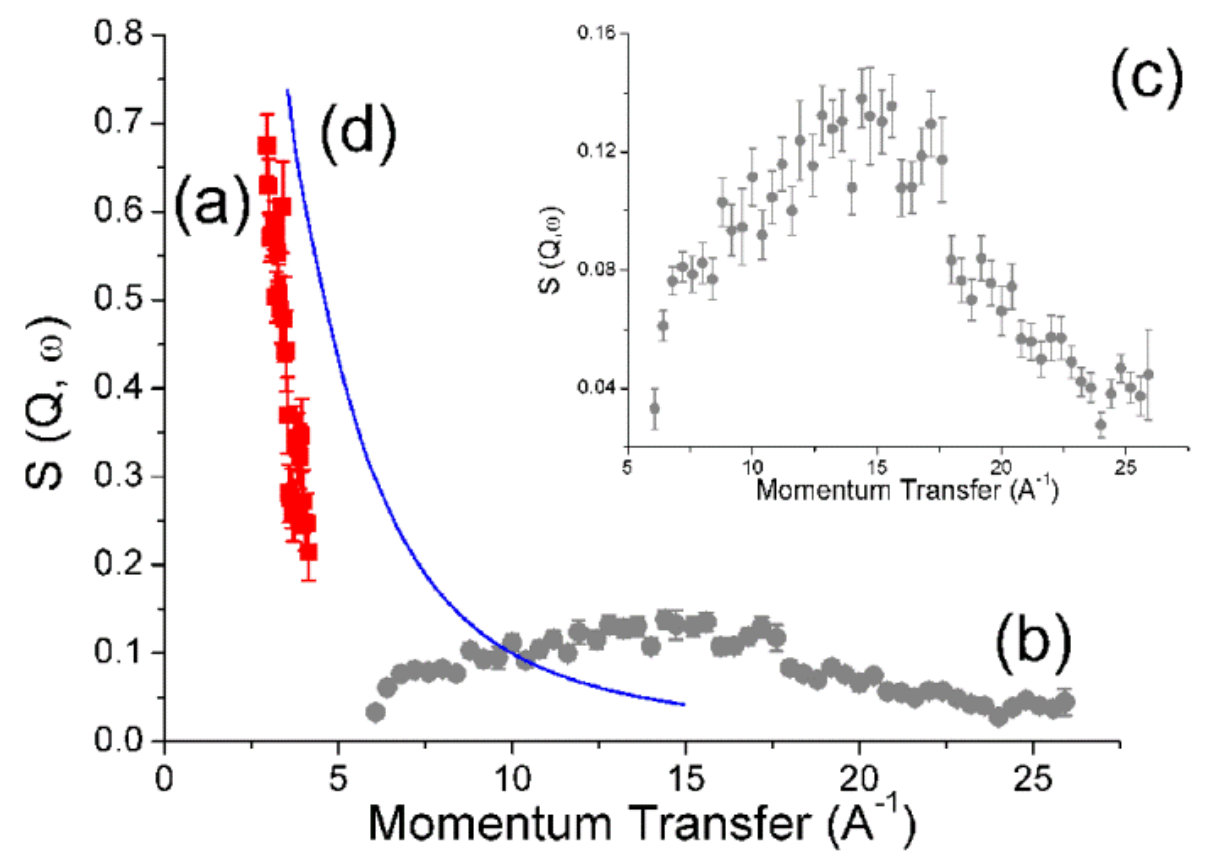

Figure 14 - The momentum transfer dependence of (a) the $810 \mathrm{~cm}^{-1}$ band of the dehydrated iron oxide sample in Fig. 9(a), (b) the $3000 \mathrm{~cm}^{-1}$ stretch feature for the reacted iron oxide sample in Fig. 8(b), (c) the $5 \leq \mathrm{Q} \leq 25 \AA$ region of (b) and (d) the calculated Q-dependence of the powder-averaged spin wave dispersion of $\alpha-\mathrm{Fe}_{2} \mathrm{O}_{3}$ shown in Fig. 12(b).

This heightened confidence in the origins of the strong band seen in the INS spectrum at $810 \mathrm{~cm}^{-1}$ for the iron oxide pre-catalyst (Fig. 9(a)) and the observation that this mode, a spinon of $\alpha-\mathrm{Fe}_{2} \mathrm{O}_{3}$, is absent from the spectrum of the reacted catalyst (Fig. 8(b)) indicates that the spinon transition plays no part in the CO hydrogenation chemistry studied here. However, given that the presence and intensity of this feature is expected to reflect, in part, physical attributes such as particle size and iron oxide crystallite homogeneity - properties thought to influence catalytic performance - a more detailed analysis of this feature with respect to different catalyst formulations may be productive in future catalyst developments. 


\section{Conclusions}

A high specification iron oxide FTS catalyst has been prepared and studied after CO hydrogenation at $623 \mathrm{~K}$ for 6 hours using INS. The following conclusions are derived.

- The INS spectrum of the dehydrated sample indicates the absence of hydroxyl groups and indicates the INS technique to be able to determine how different sample treatments may influence surface hydroxyl populations. The spectrum also indicates the presence of a spinon feature at $810 \mathrm{~cm}^{-1}$.

- The catalyst can sustain an iron time yield of $1.0 \times 10^{-7} \mathrm{~mol} \mathrm{CO} \mathrm{g}^{-1} \mathrm{Fe} \mathrm{s}^{-1}$ at 623 $\mathrm{K}$, with the reaction profile indicating methanation and water gas shift chemistry to be simultaneously occurring.

- Three distinct features are evident in the TPO profile of the reacted catalyst. In order of increasing desorption temperature, they are assigned to reactive carbon species (peak $\alpha$ ), amorphous carbon; (peak $\beta$ ); and iron carbides (peak $\gamma)$

- The INS spectrum of the reacted sample is indicative of the retention of hydrocarbonaceous species comparable to that reported in earlier studies ${ }^{10,11}$. The presence of $\mathrm{sp}^{2}$ hybridised carbon-hydrogen bonds after $6 \mathrm{~h}$ reaction at $623 \mathrm{~K}$ indicates this high surface area pre-catalyst to be more reactive than a manually prepared iron oxide sample.

- An analysis of the momentum transfer dependence of the $810 \mathrm{~cm}^{-1}$ band of the dehydrated hematite $\left(\alpha-\mathrm{Fe}_{2} \mathrm{O}_{3}\right)$ pre-catalyst unambiguously confirms this to be a magnetic feature. Further, its absence in the post-reaction INS spectrum indicates that it plays no part in the CO hydrogenation chemistry examined here. 
- Catalytic activity of iron based FTS catalysts is thought to be sensitive to physical parameters such as crystallite size and crystallite homogeneity of the pre-catalyst. Given that the presence and intensity of the $\alpha-\mathrm{Fe}_{2} \mathrm{O}_{3}$ spinon in the INS spectrum is expected, in part, to reflect these attributes, in addition to the sensitivity to hydroxyls, INS has a clear role to play in the development of structure/activity relationships for this important reaction system.

\section{Acknowledgements}

Sasol Technology UK Ltd., STFC (CCLRC) and the University of Glasgow are thanked for the provision of studentships (RW). The STFC Rutherford Appleton Laboratory is thanked for access to neutron beam facilities. Technical assistance in electron microscopy was provided by Mr Colin How (University of Glasgow).

\section{Supplemental Material}

S1, A schematic representation of the catalyst preparation apparatus; S2, A schematic representation of the micro-reactor arrangement; S3, Powder X-ray diffractogram of the pre-catalyst; S4, Raman spectrum of the pre-catalyst; S5, SEM image of the precatalyst; S6, TEM image of the pre-catalyst; S7, Post-reaction TPO profile (microreactor); S8, Post-reaction Raman spectrum (INS reactor); S9, Post reaction TPO profile (INS reactor). 
[1] J.v.d. Loosdrecht, F.G. Botes, I.M. Ciobica, A. Ferreira, P. Gibson, D.J.

Moodley, A.M. Saib, J.L. Visagie, C.J. Westrate and J.W. Niemantsverdriet, "Comprehensive Inorganic Chemistry II" (Elsevier, Oxford, 2013) pp. 525-557.

[2] A.P. Steynberg, Stud. Surf. Sci. Catal. 152, 1 (2004).

[3] M. Claeys, R. Cowan and H. Schulz, Top. Catal. 26, 139 (2003).

[4] H. Schulz, Top. Catal. 26, 1 (2003).

[5] I.P. Silverwood, N.G. Hamilton, J.Z. Staniforth, C.J. Laycock, S.F. Parker,

R.M. Ormerod and D. Lennon, Catal. Today 155, 319 (2010).

[6] I.P. Silverwood, N.G. Hamilton, A.R. McFarlane, J. Kapitan, L. Hecht, E.L.

Norris, R.M. Ormerod, C.D. Frost, S.F. Parker and D. Lennon, Phys. Chem. Chem. Phys. 14, 15214 (2012).

[7] I.P. Silverwood, N.G. Hamilton, C.J. Laycock, J.Z. Staniforth, R.M. Ormerod, C.D. Frost, S.F. Parker and D. Lennon, Phys. Chem. Chem. Phys. 12, 3102 (2010).

[8] A.R. McFarlane, I.P. Silverwood, R. Warringham, E.L. Norris, R.M.

Ormerod, C.D. Frost, S.F. Parker and D. Lennon, RSC Advan. 3, 16577 (2013).

[9] A.R. McFarlane, I.P. Silverwood, E.L. Norris, R.M. Ormerod, C.D. Frost, S.F. Parker and D. Lennon, Chem. Phys. 427, 54 (2013).

[10] N.G. Hamilton, R. Warringham, I.P. Silverwood, J. Kapitan, L. Hecht, P.B. Webb, R.P. Tooze, W. Zhou, C.D. Frost, S.F. Parker and D. Lennon, J. Catal. 312, 221 (2014).

[11] N.G. Hamilton, I.P. Silverwood, R. Warringham, J. Kapitan, L. Hecht, P.B. Webb, R.P. Tooze, S.F. Parker and D. Lennon, Angew. Chem. Int. Ed. Engl. 52, 5608 (2013). 
[12] R. Warringham, N.G. Hamilton, I.P. Silverwood, C. How, P.B. Webb, R.P. Tooze, W. Zhou, C.D. Frost, S.F. Parker and D. Lennon, Appl. Catal. A: Gen. 489, 209 (2015).

[13] N.S. Govender, M.H.J.M. de Croon and J.C. Schouten, Appl. Catal. A: Gen. 373, 81 (2010).

[14] T. Herranz, S. Rojas, F. Perezalonso, M. Ojeda, P. Terreros and J. Fierro, J. Catal. 243, 199 (2006).

[15] I.P. Silverwood, N.G. Hamilton, A. McFarlane, R.M. Ormerod, T. Guidi, J. Bones, M.P. Dudman, C.M. Goodway, M. Kibble, S.F. Parker and D. Lennon, Rev. Sci. Instru. 82, 034101 (2011).

[16] P.A. Chernavskii, J.A. Dalmon, N.S. Perov and A.Y. Khodakov, Oil \& Gas Science and Technology - Revue de l'IFP 64, 25 (2009).

[17] M. Arai, A.D. Taylor, S.M. Bennington and Z.A. Bowden, "Recent Developments in the Physics of Fluids", edited by W.S. Howells and A.K. Soper, (Adam Hilger, Bristol, 1992) pp. F321-F328.

[18] C.H. Bartholomew and R.J. Farrauto, "Fundamentals of industrial catalytic processes" (Wiley, New Jersey, 2006).

[19] M.D. Shroff and A.K. Datye, Catal. Lett. 37, 101 (1996).

[20] R. Warringham, D. Bellaire, S.F. Parker, J. Taylor, R. Ewings, C.M.

Goodway, M. Kibble, S.R. Wakefield, M. Jura, M.P. Dudman, R.P. Tooze, P.B.

Webb and D. Lennon, Journal of Physics: Conference Series 554, 012005 (2014).

[21] P.C.H. Mitchell, S.F. Parker, A.J. Ramirez-Cuesta and J. Tomkinson, "Vibrational Spectroscopy Using Neutrons" (World Scientific, Singapore, 2005).

[22] S.F. Parker, D. Lennon and P.W. Albers, Appl. Spectrosc. 65, 1325 (2011).

[23] Joint committee on powder diffraction standard card no. 86-0550. 
[24] J.I. Langford and A.J.C. Wilson, J. Appl. Crystallogr. 11, 102 (1978).

[25] J.S.J. Hargreaves, Crystallogr. Rev. 11, 21 (2005).

[26] D.L.A. deFaria, S.V. Silva and M.T. deOliveira, J. Raman Spectrosc. 28, 873 (1997).

[27] A. Kock, H.M. Fortuin and J.W. Geus, J. Catal. 96, 261 (1985).

[28] H.M. Torres Galvis, A.C.J. Koeken, J.H. Bitter, T. Davidian, M. Ruitenbeek, A.I. Dugulan and K.P. de Jong, J. Catal. 303, 22 (2013).

[29] J. Xu and C.R. Bartholomew, J. Phys. Chem. B 109, 2392 (2005).

[30] M. Ding, Y. Yang, B. Wu, T. Wang, L. Ma, H. Xiang and Y. Li, J. Mol. Catal. A-Chem. 351, 165 (2011).

[31] J. Galuszka, T. Sano and J.A. Sawicki, J. Catal. 136, 96 (1992).

[32] B. Graf, H. Schulte and M. Muhler, J. Catal. 276, 66 (2010).

[33] Joint Committee on Powder Diffraction Standard Card no. 35-0772.

[34] Joint Committee on Powder Diffraction Standard Card no. 36-1248.

[35] Joint committee on powder diffraction standard card no. 6-696.

[36] A. Sadezky, H. Muckenhuber, H. Grothe, R. Niessner and U. Pöschl, Carbon 43, 1731 (2005).

[37] M.A. Pimenta, G. Dresselhaus, M.S. Dresselhaus, L.G. Cancado, A. Jorio and R. Saito, Phys. Chem. Chem. Phys. 9, 1276 (2007).

[38] R.J. Nemanich and S.A. Solin, Phys. Rev. B 20, 392 (1979).

[39] E. Sanchez-Cortezon, M. Dieterle, Y. Uchida, G. Mestl, M. Schur and R. Schlogl, EuroCarbon 7, 9 (2000).

[40] J. McGregor, Z. Huang, E.P.J. Parrott, J.A. Zeitler, K.L. Nguyen, J.M.

Rawson, A. Carley, T.W. Hansen, J.-P. Tessonnier and D.S. Su, J. Catal. 269, 329 (2010). 
[41] I. Chamritski and G. Burns, J. Phys. Chem. B 109, 4965 (2005).

[42] Joint committee on powder diffraction standard card no. 19-629.

[43] S.J. Blundell, "Magnetism in Condensed Matter" (Oxford University Press, Oxford, 2001).

[44] M. Arai, "Neutron Scattering - Fundamentals" in Experimental Methods in the Physical Sciences (Academic Press, New York, 2013).

[45] A.H. Morrish, "Canted Antiferromagnetism, Hematite" (World Scientific, Singapore, 1994).

[46] S.N. Klausen, K. Lefmann, P.A. Lindgård, K.N. Clausen, M.F. Hansen, F.

Bødker, S. Mørup and M. Telling, J. Magn. Magn. Mater. 266, 68 (2003).

[47] E.J. Samuelsen and G. Shirane, Physica 42, 241 (1970).

[48] E.J. Samuelsen, Physica 43, 353 (1969).

[49] G.L. Squires, "Introduction to the theory of thermal neutron scattering" (Dover Publications, Cambridge, 1978).

[50] N.H. Luong, N.H. Hai, N.D. Phu and D.A. MacLaren, Nanotechnology 22 285603 (2011). 